\title{
High latitude, high coral diversity at Rapa, in southernmost French Polynesia
}

Received: 27 November 2008/ Accepted: 14 February 2009/Published online: 5 March 2009

(C) Springer-Verlag 2009

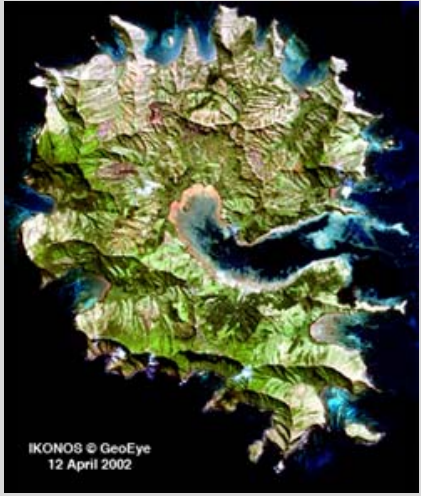

Fig. 1 Satellite image of Rapa. The large inlet on the eastern side is Haurei Bay (NASA Data Buy Purchase Program)

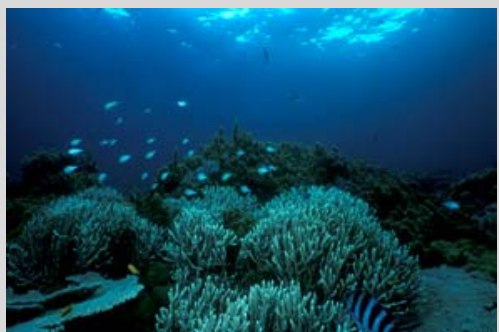

Fig. 2 A diversified coral assemblage of Haurei, with several Acropora species (photo by Yves Lefèvre, BIOSPHOTO)
Rapa $\left(27^{\circ} 28^{\prime} \mathrm{S}, 144^{\circ} 20^{\prime} \mathrm{W}\right)$, in the southern Austral Archipelago, is a small $\left(\sim 40 \mathrm{~km}^{2}\right)$ volcanic island. Mean SSTs are $20-23^{\circ} \mathrm{C}$, and this accounts for a reduced process of reef accretion. A gently sloping submarine platform (2.0-4.5 km width) surrounds the island and its steep, rugged coastline has several bays (Fig. 1). Coral distribution is sparse on the volcanic platform to $20 \mathrm{~m}$ depth, where dense macroalgae dominated by Sargassum occur; however, more diversified and abundant coral assemblages occur below this to $55 \mathrm{~m}$, and in shallower habitats inside bays.

The BIODIV Expedition (November 2002) assessed the diversity of marine organisms in Rapa. Scleractinian corals were collected during 42 dives to a maximum $58 \mathrm{~m}$ depth, covering all biotopes. Identification of this collection has revealed an unexpected high coral diversity, of 112 species from 32 genera, including five species new to science (previously, 61 species were recorded from 17 dives to a maximum of $40 \mathrm{~m}$ depth; Faure 1985). Most diverse is Acropora, with 37 species (Fig. 2), followed by Montipora (13 species), Pavona (seven species), and Leptoseris, Fungia, Favia, and Goniastrea (four species each). This was unexpected not only from Rapa's geographic isolation in the depauperate South Central Pacific (with $c a .170$ species, French Polynesia is a low diversity area), but also in comparison with other subtropical islands, such as Kermadec (17 species; Brook 1999) and Lord Howe (83 species; Harriott et al. 1995). The coral fauna of Rapa has strong similarities with that of the Cook Islands (Chevalier 1982). Goniastrea, Hydnophora, Merulina, Scolymia, and Turbinaria are recorded at Rapa and at other islands in the Australs but nowhere else in French Polynesia (Chevalier 1982). Colonies of Alveopora, Echinophyllia, and Leptoria are particularly abundant at Rapa, whereas Pocillopora and Porites, which are among the dominant corals in the Society and the Tuamotus, are rare.

Acknowledgments We thank Y. Lefèvre and S. Andréfouët for illustrations, C.E. Payri, UPF, and the Délégation à La Recherche for the organization of BIODIV, and P. Bosserelle and CRIOBE for logistic help.

\section{References}

Brook FJ (1999) The coastal scleractinian coral fauna of the Kermadec Islands, southwestern Pacific Ocean. J R Soc N Z 29:435460

Chevalier JP (1982) Reef scleractinia of French Polynesia. Proc 4th Int Coral Reef Symp 2:177-182

Faure G (1985) Reef scleractinian corals of Rapa and Marotiri, French Polynesia (Austral Islands). Proc 5th Int Coral Reef Cong 6:267-272

Harriott VJ, Harrison PL, Banks SA (1995) The coral communities of Lord Howe Island. Mar Freshw Res 46:457-465

M. Adjeroud ( $\square)$

UMR 5244 CNRS-EPHE-UPVD, Université de Perpignan, 66860 Perpignan, France

e-mail: adjeroud@univ-perp.fr

M. Pichon · C. C. Wallace

Museum of Tropical Queensland, 70-102 Flinders St, Townsville, QLD 4810, Australia

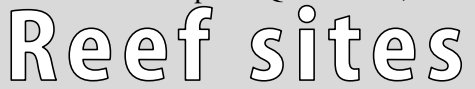

Coral Reefs (2009) 28:459

DOI $10.1007 / \mathrm{s} 00338-009-0486-8$ 